\title{
CORRECTION
}

\section{Correction to: Anomaly Detection Techniques in the Gaia Space Mission Data}

\author{
Marco Roberti $^{1} \cdot$ Alessandro Druetto $^{1} \cdot$ Deborah Busonero $^{2} \cdot$ Rossella Cancelliere $^{1} \cdot$ Davide Cavagnino $^{1} \cdot$ Mario Gai $^{2}$
}

Accepted: 16 October 2021 / Published online: 3 November 2021

๑) Springer Science+Business Media, LLC, part of Springer Nature 2021

Correction to: Journal of Signal Processing Systems (2021) https://doi.org/10.1007/s11265-021-01688-6

The original version of this article, published on 13 September 2021, unfortunately, the authors have found an error in the published version of the paper, which they didn't notice during the publication process. The address of the department is shown as the same as the Astronomic Observatory they have been working with.

Original article has been corrected.

Publisher's Note Springer Nature remains neutral with regard to jurisdictional claims in published maps and institutional affiliations.

The original article can be found online at https://doi.org/10.1007/ s11265-021-01688-6.

Marco Roberti

m.roberti@unito.it

1 Computer Science Department, University of Turin, Via Pessinetto 12, 10149 Torino, TO, Italy

2 National Inst. for Astrophysics, Astrophysical Obs. of Turin, PinoTorinese (TO), Via Osservatorio 30, 10025 Rome, Italy 